\title{
UNIVERSALITAS BAHASA DALAM KONSTELASI PEMBELAJARAN BAHASA ARAB DI INDONESIA
}

\author{
Wahyu Hanafi Putra \\ e-mail: wahyuhanafiputra@gmail.com \\ Institut Agama Islam Sunan Giri (INSURI) Ponorogo, Jawa Timur, Indonesia
}

\begin{abstract}
Abstrak: Penelitian ini bertujuan untuk menggeneralisasi konsep universalitas bahasa dan aksiologinya dalam konteks pembelajaran bahasa Arab di Indonesia. Metode yang digunakan dalam penelitian ini adalah deskriptif kualitatif. Data primer yang digunakan adalah Peraturan Menteri Agama RI No. 2 Tahun 2008 tentang arah kurikulum pembelajaran bahasa Arab di Indonesia. Data sekunder berupa diskursus pembelajaran bahasa Arab integratif yang membantu keabsahan data primer. Teknik pengumpulan data dengan dokumentasi, sedangkan analisis data menggunakan model Miles \& Hubermen, yakni reduksi data, penyajian data, penarikan kesimpulan dan verfikasi. Suatu pembelajaran bahasa Arab yang baik harus mengandung nilai universalitas bahasa. Universalitas bahasa adalah sistem lambang bunyi yang harus dilengkapi dengan dimensi-dimensi bahasa secara utuh dan sistematis. Prinsip-prinsip yang harus dipatuhi dalam universalitas bahasa meliputi prinsip fonologi, morfologi, sintaksis, dan semantik. Dengan demikian, konstelasi pembelajaran bahasa Arab di Indonesia dengan sistem universalitas bahasa akan lebih baik guna meningkatkan kemartabatan bahasa.
\end{abstract}

Kata Kunci: Universalitas Bahasa, Pembelajaran Bahasa Arab, Kurikulum, Integratif.

Abstract: This study aims to generalize the concept of language universality and its axiology in the context of learning Arabic in Indonesia. The method used in this research was descriptive qualitative. The primary data was the regulation of the Minister of Religion of the Republic of Indonesia No. 2 of 2008 concerning the direction of the Arabic learning curriculum in Indonesia. Secondary data in the form of integrative Arabic learning discourse which helps the validity of primary data. Data were collected through documentation, while data analysis used Miles and Hubermen model, namely data reduction, data presentation, drawing conclusions and verification. A good Arabic learning must have a universality of language value. The universality language is a system of sound symbols that must be complemented by the full and systematic dimensions of language. The principles which have to be followed in the universality of language including phonology, morphology, syntac, and semantic principles. Thus, Arabic language learning constellation in Indonesia using language universality system will be better to improve language dignity.

Keywords: Universality of Language, Arabic Language Learning, Curriculum, Integrative.

\section{PENDAHULUAN}

Discourse of Language baik dalam sisi kebahasaan dan pengajaranya, merupakan pengembangan dari teori-teori bahasa yang telah digagas oleh linguis, filsuf terdahulu. Linguis modern Ferdinand de Saussure, merupakan salah satu linguis yang mendobrak kemapanan studi bahasa klasik (Chaer: 2012). Ia menawarkan konsep strukturalis dalam mengkaji bahasa. Dengan berkiblat pada paham behavioristik, Saussure seakan menjadi penyempurna dalam memahami fenomena kebahasaan kontemporer sehingga masih bisa dibilang survive pada saat ini.

Bahasa Arab memiliki andil dalam perkembangan kosakata bahasa Indonesia. Namun, sisi lain pemerintah menetapkan bahasa Arab sebagai bahasa asing di Indonesia. Hal ini sebagaimana kebijakan 
politik bahasa secara nasional (Sumardi, 1974: 67). Akuisisi bahasa Arab sebagai bahasa asing kedua setelah bahasa Inggris memiliki peran dan signifikasi yang komperhensif. Jika bercermin pada jejak sejarah, pergumulan bahasa Arab di Indonesia sudah lebih dahulu dibanding masuknya bahasa Inggris. Ulama nusantara yang menimba ilmu di Timur Tengah merupakan faktor utama berkembangya bahasa Arab di Indonesia. Setelah kepulangan ulama nusantara dari beberapa negara di Timur Tengah, mereka mengajarkan materi materi agama dalam bidang fikih, akidah, tafsir, tasawuf, dan bahasa Arab dari literatur-literatur berbahasa Arab. Secara implisit, manfestasi demikian turut memberi pengaruh terhadap perkembangan bahasa Arab di Indonesia secara berkala. Ulama mengajar materi materi agama yang berbahasa Arab dengan pendekatan dan metode yang konvensional. Bahasa Arab dipandang sebagai objek bukanlah subjek. Metodologi pembelajaran bahasa Arab (PBA) saat itu dirasa sangat relevan dalam memberi pemahaman terhadap santri dan siswa. Lokasi pembelajaran dilaksanakan di langgar, surau, masjid, dan pesantren.

Seiring dengan perkembangan zaman, metodologi PBA mulai memasuki pada wilayah pendidikan formal seperti pendidikan dasar, pendidikan menengah dan pendidikan tinggi. Metodologi PBA juga merambah pada pendidikan nonformal seperti madrasah diniyah, lembaga pengembangan bahasa, dan bimbingan belajar. Eksistensi metodologi PBA juga terus berkembang dengan adanya riset-riset mutakhir dari praktisi bahasa, akademisi dan peneliti. Metodologi PBA tidak lagi dipandang sebagai subjek keberhasilan pendidikan bahasa, kini ia bisa dianggap sebagai subjek sekaligus objek keberhasilan pendidikan bahasa. Terbukti, resistensi bahasa Arab yang semula memiliki perspektif etnologis kini berdalih ke dalam perspektif metodologi.

Peraturan Menteri Agama RI Nomor 2 Tahun 2008 tentang arah kurikulum pembelajaran bahasa Arab di Indonesia, pembelajaran bahasa Arab di madrasah Indonesia dipersiapkan untuk pencapaian kompetensi dasar berbahasa yang mencakup empat keterampilan berbahasa yang diajarkan secara integral, yaitu menyimak, berbicara, membaca, dan menulis. Kemudian tujuan pembelajaran bahasa Arabnya ialah 1) mengembangkan kemampuan berkomunikasi dalam bahasa Arab baik lisan maupun tulis yang mencakup empat kecakapan berbahasa, yakni menyimak (istima'), berbicara (kaläm), membaca (qiräah), dan menulis (kitäbah). 2) Menumbuhkan kesadaran tentang pentingnya bahasa Arab sebagai salah satu bahasa asing untuk menjadi alat utama belajar khususnya dalam mengkaji sumbersumber ajaran Islam. 3) Mengembangkan pemahaman tentang saling keterkaitan antara bahasa dan budaya serta memperluas cakrawala budaya (Muradi: 2013: 134).

Menyikapi peraturan Menteri Agama RI tersebut, perlu kiranya peneliti menjabarkan ke dalam metodologi PBA yang humanis, integratif, dan faktual dengan melakukan terobosan tertentu dan memecahkan permasalahan metodologi PBA tanpa menyingkirkan metodologi yang sudah berlaku. Metodologi yang sudah berlaku akan dapat dijadikan pijakan guna memperkuat resistensi metodologi PBA berikutnya. Harus diakui, perkembangan dunia pendidikan di berbagai aspeknya akan terus melejit sembari dengan berkembangnya arus persaingan global. Tidak bisa menafikan hal ini dengan berdalih bahwa metodologi pembelajaran klasik dapat menjawab permasalahan pembelajaran modern. Semua membutuhkan proses dan penanganan yang intens. Pendidikan dan pengajaran bahasa tidak dapat dinomorduakan dengan materi 
pendidikan lain. Bahasa asing adalah kunci memahami literatur-literatur yang berbahasa asing. Sudah selayaknya metodologi pembelajaran bahasa asing terutama bahasa Arab menjadi perhatian bagi seluruh elemen masyarakat pendidikan agar menjadi pilar utama menuntaskan misi pendidikan bahasa Arab yang komperhensif.

Arah kurikulum pembelajaran bahasa Arab di Indonesia sesuai peraturan Menteri Agama RI di atas memerlukan revitalisasi metodologi dalam artian kebijakan integrasi bahasa yang merupakan keniscayaan dalam sebuah pembelajaran bahasa. Penelitian Nanik (2019) menjelaskan integrasi pembelajaran bahasa terutama bahasa Arab lebih tepat jika dilakukan di pendidikan tingkat dasar. Langkah demikian dengan paradigma bahwa pendidikan dasar merupakan pondasi dari kecerdasan linguistik. Langkah lebih lanjut kemudian mengintegrasikan pembelajaran bahasa di level pendidikan menengah, seperti hasil penelitian Makruf (2016) di MA AlMukminin Sukaharjo, Jawa Tengah yang didapati menghasilkan lulusan yang terampil berbahasa Arab aktif secara lisan dan tulisan jika diimplementasikan secara periodik dan konsisten.

Studi bahasa yang baik adalah studi bahasa yang mampu mengoptimalkan dan mengelola unsur-unsur bahasa secara komperhensif. Adanya dialektika yang baik antara unsur-unsur tersebut, merupakan formulasi dalam mengejawantahkan nilainilai kebahasaan yang tidak parsial. Kemampuan seorang praktisi, peneliti maupun pengajar bahasa dalam memberikan celah yang berkesinambungan dalam segala unsur merupakan prestasi yang harus dihargai. Tidak mudah bagi seorang pengajar bahasa untuk mendialogkan dan mengintegrasikan unsur-unsur bahasa dalam sebuah kesatuan dalam tahapan pembelajaran bahasa.

Universalitas bahasa, atau juga bisa disebut dengan kesemestaan bahasa, merupakan kajian disiplin keilmuan filsafat bahasa yang berusaha memandang bahwa bahasa merupakan sistem lambang bunyi yang harus dilengkapi berbagai dimensi dengan satu kesatuan yang sistematis. Makna dimensi di sini mencakup sistem fonologi, morfologi, sintaksis dan semantik.

Pembelajaran bahasa yang baik adalah pembelajaran bahasa yang mampu mengintegrasikan dimensi-dimensi bahasa dengan sistematis, metodologis dan objektif, begitu juga dalam pembelajaran bahasa Arab. Pembelajaran bahasa Arab merupakan salah satu pembelajaran bahasa yang sangat survive di Indonesia baik dalam jenjang pendidikan formal, non-formal, dasar, menengah maupun perguruan tinggi. Bagi penulis, pembelajaran bahasa Arab yang baik adalah pembelajaran bahasa Arab yang mampu mengintegrasikan dimensidimensi bahasa dengan sistematis dan metodologis serta selaras dengan masyarakat bahasa, atau bisa dikatakan peserta didik. Setiap pendekatan dan metode PBA pasti mempunyai sisi kelebihan dan kekurangan. Tidak semua pendekatan dan metode PBA mempunyai nilai universalitas bahasa. Disadari atau tidak, universalitas bahasa dalam PBA sangatlah penting, agar peserta didik mampu memahami esensi bahasa secara sempurna.

Penelitian ini dianggap penting guna menggeneralisasi konsep universalitas bahasa dan aksiologinya dalam konteks pembelajaran bahasa Arab di Indonesia. Dalam artian, peneliti berupaya mendeskripsikan peraturan Menteri Agama RI Nomor 2 Tahun 2008 tentang arah kurikulum pembelajaran bahasa Arab di Indonesia ke dalam metodologi pembelajaran bahasa Arab yang integratif dan humanis dengan judul "Universalitas Bahasa dalam Konstelasi Pembelajaran Bahasa Arab di Indonesia".

\section{METODE PENELITIAN}


Jenis penelitian ini adalah kualitatif. Secara substantive, penelitan ini merupakan penelitian bahasa, dan merupakan penelitian yang sistematis, terkontrol, empiris, dan kritis terhadap objek sasaran yang berupa bunyi tutur (bahasa) (Mahsun, 2004: 2). Penelitian ini bersifat deskriptif-kualitatif. Dalam aplikasinya, akan mengkaji universalitas dimensi-dimensi bahasa dalam konteks PBA.

Data primer yang digunakan adalah peraturan Menteri Agama RI No. 2 Tahun 2008 tentang arah kurikulum pembelajaran bahasa Arab di Indonesia. Data sekunder berupa diskursus pembelajaran bahasa Arab integratif yang membantu keabsahan data primer.

Teknik pengumpulan data yang digunakan adalah teknik dokumentasi. Peneliti melakukan studi dokumentasi terhadap Peraturan Menteri Agama RI No 2 Tahun 2008 tentang arah kurikulum pembelajaran bahasa Arab di Indonesia. Selanjutnya dilakukan analisis data. Tahap ini merupakan tahapan yang sangat menentukan, karena kaidah-kaidah yang mengatur keberadaan objek penelitian harus sudah diperoleh. Penemuan kaidah-kaidah tersebut merupakan inti dari sebuah aktivitas ilmiah yang disebut penelitian, betapapun sederhananya kaidah yang ditemukan tersebut (Mahsun, 2004: 117). Kemudian teknik analisis data pada penelitian ini menggunakan model Milles dan Hubermen yang meliputi reduksi data, penyajian data, penarikan kesimpulan dan verifikasi (Ismawati, 2016: 21).

\section{HASIL DAN PEMBAHASAN}

Universalitas Bahasa dalam Konstelasi Pembelajaran Bahasa Arab di Indonesia

Secara hierarki, dimensi-dimensi bahasa dalam konteks universalitas bahasa dimulai dari prinsip fonologi, morfologi, sintaksis dan terakhir semantik. Prinsipprinsip tersebut merupakan sub-linguistik mikro yang fokus kajiannya adalah analisis bahasa itu sendiri. Begitu juga telah dikemukakan di depan bahwa makna universalitas bahasa adalah bahasa merupakan sistem lambang bunyi yang harus dilengkapi berbagai dimensi dengan satu kesatuan yang sistematis. Dimensidimensi ini akan lebih baik diaplikasikan dalam konteks pembelajaran bahasa secara integratif, terutama dalam PBA. Tujuan Pembelajaran bahasa Arab sesuai Peraturan Menteri Agama RI Nomor 2 Tahun 2008 diantaranya ialah mengembangkan kemampuan berkomunikasi dalam bahasa Arab baik lisan maupun tulis yang mencakup empat kecakapan berbahasa, yakni menyimak (istima'), berbicara (kaläm), membaca (qiräab), dan menulis (kitäbah). Maka dari itu, aplikasi dimensi-dimensi bahasa dalam konteks PBA di Indonesia sebagaimana peraturan Menteri Agama RI tersebut peneliti deskripsikan sebagai berikut:

Prinsip Fonologi. Fonologi merupakan studi bunyi bahasa yang berkenaan dengan sistem bahasa, organisasi bahasa, serta merupakan studi fungsi linguistis bahasa (Kushartanti, 2007: 45). Bisa dikatakan, bahwa studi fonologi hanya menelaah bunyi bahasa yang bermakna saja, atau lebih tepatnya bunyi bahasa yang mengandung makna saja (Soeparno, 2013: 23). Dalam kajian linguistik Arab, fonologi bisa disebut dengan Tlm al-Așwāt al-Tanzìmì atau Tlm alWazāif al-Așwät, adalah cabang linguistik yang mempelajari bunyi bahasa berdasarkan aspek aturan-aturan kebahasaan (Umar, 1997: 66). Dari definisi tersebut, dapat diambil kesimpulan bahwa penyelidikan terhadap bunyi-bunyi bahasa ada dua, pertama, penyelidikan bunyi yang berfungsi membedakan semantik kata, kedua, penyelidikan bunyi-bunyi yang tidak membedakan semantik kata (Nasution, 2017: 92).

Terdapat tiga komponen yang ada dalam aturan fonologi, yakni butir, organisasi (urut) dan unsur suprasegmental. 
Ketiga komponen tersebut akan bekerja sama dalam membentuk kata. Kemudian, bagaimana peran ketiga komponen tersebut dalam subsistem fonologi? Jika butir mempunyai peran yang penting, maka peran organisasi atau suprasegmental dapat menjadi ringan. Jika unsur suprasegmental sangat berperan, maka kedua komponen lainnya dapatlah mempunyai peran yang ringan. Demikian juga, jika organisasi berperan, maka butir dan unsur suprasegmental dapat berperan ringan (Soepomo, 2001: 196).

Generalisasi dan mekanisme kinerja ketiga komponen fonologi ini dalam PBA adalah, guru memulai mengidentifikasi butir-butir fonem yang akan diajarkan, sebagai contoh guru mengambil al-Harf alHijaiyyah sebagai bahan materi ajar. Kemudian dalam organiasasinya, guru dapat mensimulasikan dan melafalkan bunyi-bunyi al-Harf al-Hijaizyah dengan tata cara yang benar dengan memperhatikan unsur suprasegmental sehingga padanan makna bunyi yang dihasilkan bisa dimengerti oleh siswa. Guru juga bisa mensimulasikan pengembangan fonem-fonem yang disusun dengan bentuk jumlah ismiyyah maupun jumlah fi'liyyah. Pada saat itu, guru bisa menggunakan Tariqah al-Sam'iyyah alSyafawiyyah (Metode Audiolingual). Dalam aplikasinya, setelah guru mensimulasikan dan melafalkan fonem-fonem tertentu dengan aturan yang benar baik dari sisi tekanan, durasi, nada, aksen, intonasi dan ritme, siswa sesekali bisa disuruh menirukan apa yang telah dilafalkan oleh guru baik secara individu maupun kelompok. Kemudian guru sesekali memberikan rangsangan kepada siswa untuk mengidentifikasi arti fonem-fonem yang telah ducapkan dalam bentuk jumlah ismiyyah maupun jumlah fi'liyyah. Kegiatan ini bisa dilangsungkan secara terus-menerus sehingga siswa mampu melafalkan fonemfonem yang diajarkan dengan baik dan siswa mampu mengidentifikasi arti pembentukan fonem dalam susunan jumlah. Prinsip Morfologi. Morfologi adalah ilmu bahasa tentang seluk beluk bentuk kata (struktur kata) (Arifin dkk, 2009: 2). Dengan kata lain, morfologi merupakan subdisiplin linguistik yang menelaah bentuk, proses, dan prosede pembentukan kata (Soeparno, 2013: 29). Dalam linguistik Arab, morfologi bisa dikatakan sebagai Ilm al-Ṣarf, Ilm alNiżam al-Sarfy atau Tlm al-Isytiqāq (Hasan, 1979: 81). Dalam kajiannya lebih menekankan pada tekstur kata dari sisi bentuknya, perubahan kata baik penambahan maupun pengurangan serta pengaruhnya terhadap makna (Daud: 106). Dari pengertian tersebut dapat ditinjau bahwa morfologi adalah ilmu bahasa yang membahas perubahan bentuk kata baik secara derivatif maupun inflektif.

Hampir sama dengan komponenkomponen fonologi, terdapat dua komponen dalam prinsip morfologi, yakni komponen butir pembentukan kata, dan komponen organisasi (urutan). Kedua komponen tersebut merupakan komponen inti yang harus berdialektika dan bekerja sama dengan baik. Peran pembentukan kata, baik secara derivatif maupun inflektif harus memperhatikan aturan-atauran main yang dimiliki. Konstruksi morfologis yang dimiliki suatu kata akan memberikan makna sekaligus pengertian berdasarkan perubahan kata yang dibentuk. Jika peran konstruksi pembentukan kata berjalan dengan baik, maka organisasi atau aturan setelahnya akan bekerja demi membentuk sebuah citra kolokasi (Kholison, 2016: 159), sehingga, makna-makna yang dihasilkan dari proses kolokasi dapat digunakan saat itu dan dikembangkan lebih lanjut.

Aplikasinya dalam PBA adalah, guru bisa memulai dengan mengidentifikasi butirbutir verba yang akan dibentuk secara derivatif maupun inflektif. Kemudian dalam organisasinya, guru memberikan contohcontoh pembentukan verba (al-fi'lu) secara 


\section{P-ISSN: 2715-8098 \\ E-ISSN: 2715-8101}

derivatif dengan menyesuaikan șighat (bentuk) dan warn (susunan) verba tersebut. Istilah ini dalam Tlm al-Sarf disebut dengan Tașrif Isțtilabi. Pembentukan verba bisa menggunakan bentuk al-fi'lu al-mujarrad (verba yang sepi dari tambahan) ataupun alfi'lu al-marid (verba yang mengalami proses afiksasi) yang kemudian akan dikembangkan menjadi nomina (al-ismu) karena proses derivasi. Setelah guru memberikan contohcontoh pembentukan verba dengan tuntas, mulai dari fi'lu al-mädì, fi'lu al-mudāri', mașdar, ismu al-fä'il, ismu al-maf'ül, al-amr, alnaby, ismu al-zamān wa al-makān, maka guru menganjurkan siswa untuk menghafalkan konstruksi-konstruksi perubahan verba tersebut dengan mengamati pola wazn al-fi' baik dari bentuk al-fi'lu al-mujarrad ataupun al-fi'lu al-marid. Siswa dianjurkan untuk mengulang-ulang verba yang telah dihafal, atau bisa dilakukan dengan teknik drill. Kegiatan ini diasumsikan bahwa keberhasilan pembelajaran morfologi biasanya tidak lepas dari kegiatan hafalan siswa. Setalah itu, guru bisa menggunakan salah satu bentuk konstruksi kata, baik dari sisi verba (al-fi'lu) maupun nomina (al-ismu) dalam jumlah mufìdah. Kemudian siswa dianjurkan untuk mengidentifikasi pola perubahan struktur kata tersebut berdasarkan konstruksi kata yang telah dihafal sebelumnya.

Prinsip Sintaksis, prinsip ini menduduki posisi ketiga pasca prinsip fonologi dan morfologi. Sintaksis adalah pengaturan dan hubungan antara kata dengan kata, atau dengan satuan-satuan yang lebih besar dari itu dalam bahasa. Satuan yang terkecil dalam sintaksis adalah kata (Kridalaksana, 2001: 199). Sedangkan, dalam terminologi yang lain dijelaskan bahwa sintaksis adalah studi tentang hubungan yang mengaitkan antar kata dalam suatu jumlah dan menjelaskan fungsinya (Daud: 168). Dalam terminologi linguistik Arab, pengaturan antar kata dalam satu kalimat, antar kalimat (jumlab) dalam klausa atau wacana merupakan kajian $\mathrm{Tlm}$ alNahwi, bahkan hubungan itu tidak menimbulkan makna mgramatikal, tetapi juga mempengaruhi baris (al-syakl) akhir masing-masing kata yang bisa disebut dengan i'rāb (Nasution, 2017: 132). Pembahasan sintaksis dirasa sangat penting dalam studi linguistik, karena di dalamnya memuat seluruh aturan-atauran kebahasaan yang diajdikan referensi dalam pembentukan butir-butir bahasa secara substantive dan formative.

Seperti halnya kedua prinsip sebelumnya, prinsip sintaksis mempunyai beberapa komponen yang harus dipatuhi dalam keberlangsungannya. Komponen sintaksis ialah butir (kata dan atau tanpa imbuhan) (Soepomo, 2001: 194), organisasi (urutan), dan unsur suprasegmental (lagu). Bagaimana kerja komponen sintaksis tersebut? Ketiga sarana atau komponen sintaksis itu saling bekerja sama, bahu membahu merupakan satu sistem yang lengkap tetapi tidak berlebihan. Berkat adanya sistem itulah, maka bahasa menjadi sarana komunikasi yang baik, yaitu yang dapat menyampaikan pesan secara jelas dengan cara yang sangat efisien (Soepomo, 2001: 191). Pemilihan butir kata secara fungsional akan membawa pada aturan yang dipakai dan kemudian akan berpengaruh pada lagu. Komponen ini merupakan kesatuan yang utuh dalam membentuk sebuah konvensi bahasa verbal dan non verbal. Konstruksi bentuk kata dengan prinsip sintaksis lebih banyak dikaji dan digunakan daripada kedua prinsip sebelumnya.

Bagaimana aplikasinya dalam PBA di Indonesia? Seperti yang telah diketahui, bahwa komponen yang harus ada dalam prinsip sintaksis adalah butir, organisasi dan unsur suprasegmental. Dalam perkembangan belajar bahasa Arab yang bertitik tekan pada prinsip sintaksi ( $T$ lm alNahwi), seorang guru harus memilih pendekatan dan metode yang tepat, karena

\section{2 |Wahyu Hanafi Putra}


dalam pembelajaran ini akan lebih menekankan pada hubungan kata dengan kata lain dalam suatu jumlah, serta fungsi kata. Maka dari itu akan lebih baik jika pembelajaran ini menggunakan pendekatan struktural (al-Madkhal al-Bināi), dan metode gramatika-terjemah (Tariqah al-Qawāid wa alTarjamah). Penggunaan metode ini sering dijumpai dalam PBA di Pondok Pesantren Salafiyyah, karena dalam pesantren tersebut, tujuan PBA adalah agar santri mampu dan terampil dalam membaca, menganalisis, dan menerjemahkan teks kitab kuning dengan baik dan benar. Mula mula guru mengajarkan kaidah-kaidah bahasa Arab degan sistem hafalan nazm, yang di dalamanya meliputi sisi ontologi, epistemologi dan aksiologi kaidah bahasa Arab. Siswa menghafal kaidah-kaidah tersebut secara individu maupun kelompok sembari guru mengajarkan maksud dari konten materi di dalam kelas. Kemudian dalam organisasinya, setelah siswa hafal mengenai kaidah-kaidah bahasa Arab sesuai tema, guru bisa menyuruh siswa untuk membaca teks kitab kuning tanpa syakl. Dari situ, siswa akan terlatih membaca dan menganalisis kedudukan kata, hubungan kata dengan kata yang lain dalam suatu jumlah berdasarkan pemahaman konsep kaidah bahasa Arab yang telah dihafalkan sebelumnya. Setalah itu, siswa dianjurkan untuk menterjemahkan teks kitab kuning yang telah dibaca. Agar hasil pembelajaran menjadi lebih baik, kegiatan ini harus dilakukan secara terus menerus dan berkala. Metode ini bisa diasumsikan paling ampuh dalam melatih siswa untuk terampil membaca teks Arab dengan baik dan benar serta memahami konten teks.

Prinsip Semantik, semantik adalah bagian dari struktur bahasa yang berhubungan dengan makna, ungkapan atau wicara, sistem, atau penyelidikan makna suatu bahasa pada umumnya (Kridalaksana, 2001: 193). Dalam terminologi lain, semantik adalah studi tentang makna, atau ilmu yang mempelajari tentang makna, atau cabang linguistik yang mempelajari tentang makna (Umar, 1982: 11). Dalam linguistik Arab, disiplin ilmu ini disebut dengan berbagai istilah, yaitu "Ilm al-Dalälab" dan "Ilm al-Ma'nā", bahkan disebut "Simantike" (Nasution, 2017: 147). Istilah-istilah ini didapat jika menelaah karya-karya semantik yang ditulis oleh linguis Arab modern, terutama pasca Breal muncul istilah "semantics", maka akan didapati keberagaman upaya dalam mencari padanannya dalam bahasa Arab yang dirasa paling tepat seperti halnya ketiga istilah tersebut (Kholison, 2016: 5). Apapun istilah yang telah dideklarasikan, secara garis besar semantik adalah studi tentang makna, penyeledikan terhadap makna yang berdasarkan teori-teori makna. Konsep makna yang ada dalam semantik adalah berdasarkan objek formal masing-masing. Akan disebut sebuah makna jika sudah diselidiki kebenarannya dengan pendekatan dan teori makna.

Komponen-komponen yang harus ada dalam prinsip semantik sama halnya dengan ketiga prinsip sebelumnya, yakni butir, organisasi dan unsur suprasegmental (Soepomo, 2001: 198). Ketiga komponen tersebut harus mampu bekerja sama dan berdialektika guna menemukan konstruksi makna pada sebuah wacana. Penyelidikan gejala-gejala makna dapat diakses dengan menggunakan salah satu sudut pandang teori semantik. Penyelidikan harus mematuhi organisasi yang telah ditentukan agar inferensi makna yang dihasilkan tidak jauh dari yang dimaksud. Sering dijumpai interpreter yang tidak mematuhi ramburambu dalam melakukan olah interpretasi makna dalam sebuah wacana teks. Sehingga makna yang dihasilkan jauh dari yang dimaksud dan berdampak pada perubahan konstruksi makna kata jika dihubungkan dengan kata yang lain. Selain itu, dalam mengolah suatu makna, seorang interpreter juga harus mempertimbangkan sisi 
historisitas makna dan perkembangannya dalam kurun tertentu. Istilah ini dalam studi linguistik sering disebut dengan pendekatan pankronik.

Bagaimana aplikasi prinsip semantik dalam PBA di Indonesia? Studi semantik biasanya dilakukan oleh mahasiswa jurusan bahasa di berbagai perguruan tinggi di Indonesia. Semantik merupakan prinsip terakhir dalam Universalitas bahasa. Sebelum mempelajari semantik, diharapkan mahasiswa mampu memahami prinsip fonologi, morfologi, dan sintaksis, karena materi tersebut menjadi prasyarat mempelajari semantik. Dalam PBA yang berorientasi pada materi semantik, langkah pertama adalah, dosen bisa menjelaskan teori-teori makna berdasarkan pendekatan semantik. Setelah dosen mengajarkan teoriteori makna, bisa diambil contoh teori sinonim (mutaräddifat), dosen bisa menjelaskan analisis teori tersebut dalam wacana teks. Dosen bisa mengambil salah satu contoh surat dalam al-Qur'an. Langkah selanjutnya dosen bisa menyuruh mahasiswa untuk mengidentifikasi kata-kata yang mungkin akan dijadikan objek penelitian dalam surat tersebut. Misalnya, mahasiswa mengambil kata-kata yang sekiranya memiliki nilai sinonim (mutaräddifat). Setelah diambil beberapa kata fokus, mahasiswa melakukan tahap analisis kritis terhadap kata-kata sinonim tersebut dengan teori mutarädifat. Kemudian, konstruksi makna yang dihasilkan dari tahap analisis tersebut sudah bisa dipresentasikan.

\section{Aksiologi Universalitas Bahasa dalam Pembelajaran Bahasa Arab}

Prinsip pengajaran bahasa dengan sistem universalitas bahasa adalah dengan mengintegrasikan dimensi-dimensi bahasa ke dalam suatu wacana yang utuh. Universalitas bahasa dalam kontestasi PBA adalah mengajarkan materi bahasa Arab berdasarkan dimensi bahasa secara sistematis, metodologis dan ilmiah, yang dimulai dari prinsip fonologi, prinsip morfologi, prinsip sintaksis dan prinsip semantik.

Manfaat dari universalitas bahasa dalam PBA adalah, agar siswa mampu memahami fenomena-fenomena bahasa Arab berdasarkan pendekatan prinsip masing-masing (fonologi, morfologi, sintaksis, dan semantik). Bahasa Arab tidak hanya dikaji secara normatif, akan tetapi lebih ke dalam hal yang bersifat objektif, empiris dan ilmiah. Upaya demikian akan menjadikan kemartabatan bahasa Arab lebih unggul.

\section{SIMPULAN}

Arah kurikulum pembelajaran bahasa Arab di Indonesia sebagaimana diatur dalam peraturan Menteri Agama RI Nomoe 2 Tahun 2008 dapat dideskripsikan sebagai revitalisasi dan rekonstruksi metodologi pembelajaran bahasa Arab yang integratif dan humanis. Metodologi ini mengarah kepada aspek universalitas bahasa, yakni memandang bahasa sebagai sistem lambang bunyi yang memiliki dimensi-dimensi bahasa secara utuh. Bahasa Arab sebagai kesatuan yang utuh yang memiliki berbagai dimensi (fonologi, morfologi, sintaksis, dan semantik), tidak harus dikaji secara normatif, akan tetapi harus bangkit dari kemapanan tersebut dan mengkaji bahasa Arab yang lebih objektif, empiris, dan ilmiah. Hal ini dilakukan agar siswa/mahasiswa memahami fenomenafenomena bahasa Arab secara ilmiah. Dengan tujuan akhir meningkatkan kemartabatan bahasa.

\section{DAFTAR RUJUKAN}

Chaer, A. 2012. Linguistik Umum. Jakarta: Rineke Cipta.

Hasan, T. 1979. al-Lughah al-'Arabiyyah Ma'nāhà wa Mabnāhā. Kairo: al-Haiah al-Mișsriyyah al-'ĀAmmah li al-Kitāb.

Ismawati, E. 2016. Metode Penelitian Pendidikan Bahasa dan Sastra. Yogyakarta: Penerbit Ombak.

\section{4 |Wahyu Hanafi Putra}


Izzan, A. 2004. Metodologi Pembelajaran Bahasa Arab. Bandung: Humaniora.

Kholison, M. 2016. Semantik Bahasa Arab; Tinjauan Historis, Teoritis, dan Aplikatif. Sidoarjo: Lisan Arabi.

Kridalaksana, Harimurti. 2001. Kamus Linguistik Cet. ke-5. Jakarta: Gramedia Pustaka Utama.

Kushartanti. 2007. Pesona Bahasa; Langkah Awal Memahami Linguistik. Jakarta: Gramedia Pustaka Utama.

Daud, M. tt. al-'Arabiyyah wa Tlm al-Lughah al-Hadis. Kairo: Dar Gharib.

Mahsun. 2004. Metodologi Penelitian Bahasa: Tahapan strategi, Metode dan Tekniknya, "Edisi Revisi". Jakarta: PT. RajaGrafindo Persada.

Makruf, I. 2016. Manajemen Integrasi Pembelajaran Bahasa Arab di Madrasah Berbasis Pondok Pesantren. Jurnal Cendekia, 14 (2).

Muradi, A. (2013). Tujuan Pembelajaran Bahasa Arab di Indonesia. Jurnal AlMaqoyis 1 (1).

Nanik S. 2019. Universalitas Bahasa dalam Konteks PBA li al-Marhalah alIbytidaiyyah. Jurnal Qalamuna, 10 (1).
Nasution, S. 2017. Pengantar Linguistik Bahasa Arab. Sidoarjo: Lisan Arabi.

Pranowo. 2015. Teori Belajar Babasa. Yogyakarta: Pustaka Pelajar.

Soeparno. 2013. Dasar-dasar Linguistik Umum. Yogyakarta: Tiara Wacana.

Soepomo. 2001. Filsafat Bahasa. Yogyakarta: Muhammadiyah University Press.

Suroso, E. 2016. Psikolinguistik. Yogyakarta: Penerbit Ombak.

Umar, A. M. 1982. Ilm al-Dalälah. Kuwait, Maktabah Dār al-'Arabiyyah li alNashr wa al-Tauzī.

Umar, A. M. 1997. Dirāsah al-Șaut alLughawy. Kairo: Alam al-Kutub.

Arifin, Z. \& Junaiyah. 2009. Morfologi: Bentuk, Makna, dan Fungsi "Edisi Revisi”. Jakarta: Grasindo. 